\title{
Unidades fraseológicas en un corpus histórico del español en Chile
}

\author{
Phraseological units within a historical corpus \\ of the Spanish language
}

\author{
PATRICIA PORMA JIMÉNEZ \\ SUSANA SERRA SEPÚLVEDA \\ Universidad de Chile, Facultad de Filosofía y Humanidades. Chile. \\ Correo electrónico: patriciaporma@ug.uchile.cl \\ Universidad de Chile, Facultad de Filosofía y Humanidades. Chile. \\ Correo electrónico: sserra@uchile.cl
}

El presente trabajo aborda, desde la gramática de base léxica, la descripción de unidades fraseológicas o pluriverbales dentro de un corpus histórico de la lengua espańola. Este corresponde a una muestra de testimonios de la recopilación de literatura oral realizada en Chile por el Dr. Rodolfo Lenz entre fines del siglo XIX y comienzos del XX, patrimonio cultural y lingüístico que se encuentra aún prácticamente inexplorado. Nuestro trabajo consistió en la clasificación y descripción de las unidades pluriverbales de tipo léxico halladas dentro de este corpus histórico del español de Chile, procedimiento que se realizó de acuerdo con nuestra propuesta taxonómica para este tipo de unidades léxicas. Entre los resultados más relevantes de esta búsqueda, está el hallazgo de unidades léxicas no testimoniadas en fuentes lexicográficas o corpus históricos del español, y el registro de otras que podrían considerarse el antecedente de unidades fraseológicas que perviven hasta la actualidad. Con los resultados de este trabajo se busca aportar al mayor y mejor conocimiento de la lengua española en Chile, así como confirmar la aplicabilidad de nuestra propuesta de clasificación para las unidades léxicas complejas.

\section{Rodolfo Lenz.}

Palabras clave: unidades fraseológicas, unidades léxicas pluriverbales, español de Chile,

This article aims the description of phraseological units within a historical corpus of the Spanish language. This corresponds to a sample of testimonies from the compilation of oral literature carried out in Chile by Dr. Rodolfo Lenz, cultural and linguistic heritage that is still practically unexplored. The work consisted in the description and categorization of such phraseological units according to a personal proposal. Among the most relevant results of this search, is the finding of lexical units not attested in lexicographic sources or historical corpus of Spanish, and the registry of others that could be considered the antecedent of phraseological units that survive to the present time With the results 
of this work we seek to contribute to the better knowledge of the Spanish language in Chile, as well as to confirm the applicability of our classification proposal for complex lexical units.

Key words: phraseological units, pluriverbal lexical units, chilean Spanish, Rodolfo Lenz.

\section{INTRODUCCIÓN}

El estudio histórico de la lengua debe contar con datos empíricos confiables que reflejen sus distintos estados en las diferentes sincronías o períodos históricos. Sin embargo, las fuentes documentales, incluso las no literarias, por las condiciones singulares de la comunicación escrita, reflejan un estilo y nivel de lengua caracterizado por el apego, en mayor o menor medida, a la cultura letrada y, en consecuencia, a un restringido sector de la sociedad.

Rodolfo Lenz fue un filólogo y fonetista de origen alemán que llegó a Chile en 1890 y que se convirtió en el propulsor de los estudios propiamente lingüísticos, etnográficos y folclóricos en nuestro país. En línea con su orientación cientificista para el estudio de la lengua, el maestro alemán dedicó grandes esfuerzos a la recolección de corpus de habla, sobre todo de manifestaciones de la literatura oral y cultura popular en Chile.

El presente trabajo aborda, desde la gramática de base léxica, la descripción de las unidades llamadas fraseológicas o pluriverbales en un corpus consistente en una acotada muestra de la recopilación de literatura oral realizada por Rodolfo Lenz, la que constituyen en sí un valioso patrimonio histórico que hasta ahora se encuentra prácticamente inédito y sin estudio. Esta investigación de orden cualitativo y exploratorio, consistió, en primer lugar, en detectar unidades léxicas pluriverbales en este corpus diacrónico, y, en segundo lugar, en realizar una descripción de las mismas en cuanto a su significado y clasificación, siguiendo nuestra propuesta taxonómica para este tipo de unidades léxicas.

\section{Marco teórico}

Las unidades fraseológicas (UF) tradicionalmente se han conocido como unidades complejas, pluriverbales o plurilexemáticas. Son de tipo léxico o textual. Se caracterizan por expresar un solo concepto (las de tipo léxico) o una sola idea central (las de tipo textual), independientemente del número de palabras de que consten. Pertenecen al plano léxico los compuestos sintagmáticos (caja fuerte, guardia civil, media luna), las colocaciones con verbo "soporte" (dar permiso) y las locuciones (ser [algo] harina de otro costal). Pertenecen al plano textual algunas fórmulas (buenos dias, ¿qué tal?), las citas y las paremias (chancho limpio nunca engorda), entre otras. Aquí nos haremos cargo de las unidades fraseológicas en el nivel léxico. Consecuentemente, a continuación trataremos sobre composición, colocación y locución. La finalidad de este trabajo es establecer los rasgos que, en nuestra opinión, permitirían 
definir distintamente cada tipo de unidad fraseológica. En cada caso, empezaremos por referir las propiedades que la tradición gramatical les ha adscrito, para en seguida mediante ejemplos y contraejemplos (tomados a veces de la misma bibliografía), argumentar en favor de nuestra postura.

\subsection{Composición}

La Nueva Gramática (2010) llama composición al proceso por el cual dos o más palabras crean conjuntamente una nueva palabra y, por tanto, una nueva designación. Tradicionalmente se ha distinguido entre compuestos léxicos o propios (sacapuntas, duermevela, mandamás) y compuestos sintagmáticos (casa de cambios, tinta china, pájaro carpintero). En estos últimos, el grado de lexicalización no se ha cumplido del todo, de manera que los miembros del compuesto mantienen una relación sintáctica (del tipo núcleo + modificador, como en los ejemplos), por un lado, y conservan su autonomía gráfica, por otro. En español, algunas palabras compuestas se encuentran claramente en un proceso de transición, según evidencian estos usos del español de Chile: traje de baño (compuesto por sinapsia), traje baño (compuesto por disyunción) y trajebaño (compuesto por yuxtaposición); o bien corte de circuito, corte circuito y cortocircuito. De ambos tipos de compuestos, en esta comunicación nos interesan los sintagmáticos, que pueden darse en sus dos formas, por sinapsia o por disyunción. La bibliografía ha descrito estos compuestos como sintagmas "fijos", rasgo que compartirían con las locuciones. Por el contrario, las colocaciones han sido caracterizadas tradicionalmente como sintagmas "semi-fijos", de modo tal que, no siendo del todo "libres", tampoco formarían combinaciones estrictamente "fijas". Veremos en qué medida estas aserciones se ajustan a la realidad lingüística -según perspectiva nuestra.

\subsection{Colocación}

Este es uno de los términos más controvertidos de la lexicología moderna. Se ha entendido de dos maneras fundamentalmente: 1) combinación frecuente y preferente de dos unidades léxicas (pingües beneficios, nariz aguileña, miedo cerval, cometer errores solicitar encarecidamente, etc.), y 2) combinación restringida de dos lexemas (L1: base y L2: colocativo), donde uno de ellos selecciona al otro. En lexicología española, quienes defienden este segundo concepto de colocación, tienen, a su vez, miradas distintas en relación con la "direccionalidad" de la selección léxica. Alonso Ramos (2004, 2007, 2012) estima que dicha selección se cumple desde la base al colocativo (por ejemplo, en miedo cerval el sustantivo selecciona al adjetivo; en solicitar encarecidamente, el verbo al adverbio). Contrariamente, Bosque (2001a, 2004,, 2011) plantea que la selección es más bien al revés, atendiendo al hecho de que el colocativo -así en los ejemplos- es siempre un predicado, y de que toda unidad léxica predicativa se define en función de los argumentos que selecciona. Ambos autores aplican una teoría distinta para explicar el comportamiento sintáctico entre los colocados (base y colocativo). Alonso Ramos se 
sustenta en la propuesta de las "funciones léxicas" de Mel'cuk (1996, 2001); ${ }^{1}$ Bosque, por su parte, introduce el concepto de "clase léxica", que aquí defendemos. Según este autor, un predicado no selecciona necesariamente "piezas" léxicas, sino verdaderas "clases" de palabras con propiedades semánticas afines. Así, en pingües beneficios, la relación no sería exclusiva entre estos dos lexemas, toda vez que el adjetivo se predica de otros sustantivos de intensión similar a la de beneficios, como, por ejemplo: ganancias, sumas, recompensas, honorarios, intereses, dividendos, etc., etc. (cfr. Redes). De este modo, Bosque cuestiona, por una parte, que una colocación sea una combinación "binaria" de lexemas, como ha sido habitual sostener en lexicología; por otra parte, explica por qué la combinación es "frecuente" en español, y no azarosa. La frecuencia, por tanto, responde a razones fundamentalmente lingüísticas en estos casos. Por el carácter restringido de la selección léxica en este tipo de sintagmas, algunos autores piensan que se trata de semifrasemas, y los sitúan a medio camino entre las combinaciones "libres" y las "fijas", según ya se señaló. A juicio nuestro, y siguiendo las propuestas de Bosque, estas construcciones tienen las mismas características que los mal llamados sintagmas libres, en la medida en que todo sintagma en la lengua presenta algún tipo de restricción (sea sintáctica o semántica). Por ejemplo:

el adjetivo rojo impone como único requisito de selección que se predique de un 'objeto físico', como por ejemplo, cofre en el cofre rojo, pero dicha selección, aunque débil, existe, puesto que resulta impensable decir *aminata roja. Por tal motivo, no sólo en los sintagmas libres hay principios de selección léxica que regulan la combinación entre sus miembros, sino que las colocaciones responden a los mismos principios de selección, sólo que en estos casos las propiedades léxicas de la base, de mayor carga intensional, hacen que las restricciones combinatorias entre los elementos sean más estrictas, pudiendo incluso llegar a ser exclusivas, com o en el mencionado ejemplo de torrencial que, sabemos, sólo se dice de lluvia. (Osorio y Serra 2012: 107)

Consiguientemente, desestimamos este concepto de colocación, habida cuenta de que la relación entre los colocados es de orden predicativo, es decir, prototípica de los sintagmas "libres". En cambio, defendemos otro, en el que se observa la presencia de un verbo "soporte" más un sustantivo de evento, como en prestar ayuda 'ayudar', dar un paseo 'pasear', tomar decisiones 'decidir', etc. En estos casos, la combinación entera funciona como una sola unidad léxica y la predicación se lleva a cabo mediante los nombres (eventivos),

\footnotetext{
${ }^{1}$ Una función léxica (FL) es un sentido o un papel semántico-sintáctico tal que su expresión depende del lexema al que esta FL se aplica. Por ejemplo, si aplicamos la FL VER 'como tiene que ser' a la base (o palabra llave) "defensa", el valor resultante, en español, es "legítima". Así es como defensa y legítima forman una colocación. La misma función léxica aplicada a distintas bases arroja valores distintos. Veamos: VER (sospecha) = fundada; VER $($ precio $)$ = justo; VER (palabra) = precisa, etc., etc. En todos los ejemplos, según se observa, es en función del significado de la base que se selecciona el colocativo.
} 
no mediante los verbos. En construcciones como estas, el verbo tiene un significado muy general, vago o abstracto, en contraposición con el nombre, que posee su sentido pleno. Se trata, entonces, de predicados complejos con sentido unitario, razón por la cual son muchas veces intercambiables por verbos simples (así en los ejemplos). A estos verbos se los ha llamado también verbos de apoyo (Alonso Ramos 2004) o verbos ligeros (Bosque 2001b). El problema radica en el grado de "desemantización" que se les atribuye. Alonso Ramos (2004) sostiene que estos son semánticamente vacíos; Bosque prefiere afirmar que tienen significado aspectual, por cuanto denotan en diferente medida "the coming into existence of an event or state of affairs" (Bosque 2001b: 28). De Miguel (2008, 2011) propone que entre el verbo y el nombre se produce una concordancia de rasgos léxicos. Por ejemplo, la combinación hacer + exhibición (en hacer una exhibición) es posible porque tanto el verbo como el nombre tienen significado eventivo. Pensamos que cada una de las afirmaciones precedentes merece tenerse en cuenta. Que en estas estructuras el verbo es de naturaleza especial, lo muestra el hecho de que carece por sí mismo de estructura argumental. Por ejemplo, en "Ximenita dio un paseo por el jardín", el sintagma un paseo funciona como complemento directo de dar, pero este no lo selecciona (en su sentido pleno, dar selecciona 'objetos' como complemento directo, no 'eventos' (cfr. "Ximenita me dio una flor/ un libro/ un regalo"). Asimismo, cuando es ligero, el verbo no posee argumento externo. En nuestro ejemplo, Ximenita es argumento externo de un paseo, y no de dar (cfr. El paseo de Ximenita por el jardín). En conclusión, el verbo actúa como una suerte de operador en tanto en cuanto hace posible la predicación mediante el nombre. Ahora bien, no significan exactamente lo mismo mirar que echar una mirada, por poner otro ejemplo. Cualquier hablante de español es capaz de percibir que difieren en cuanto a la "puntualidad" del evento que designan (-puntual y +puntual respectivamente). Lo interesante es advertir que este rasgo de aspectualidad que añade el verbo a la construcción entera no es nada ajeno al que este posee en sintagmas como "echar un papel al basurero" o "echar a Pepe de la casa", donde sí selecciona al objeto con que forma sintagma. En consecuencia, en las colocaciones de verbo soporte + nombre eventivo el verbo, si bien no es pleno en el sentido de que no predica, no puede decirse en rigor que sea "vacío", que carezca de significado.

\subsection{Locución}

Tradicionalmente se la entendió como una combinación fija con sentido figurado (tomar el toro por las astas, dorar la pildora, llover sobre mojado, etc.). ${ }^{2}$ En la actualidad se la define más bien como una unidad léxica pluriverbal con opacidad semántica y fijación estructural. En efecto, el significado de la unidad compleja dorar la píldora, por ejemplo, no

\footnotetext{
${ }^{2}$ Cuestionamos que se trate de una "combinación" porque sus componentes no contraen una relación sintagmática (el conjunto se comporta como una sola unidad léxica); por otra parte, el sentido figurado en una locución, en un gran número de casos, no impide interpretar o reconstruir su significado.
} 
se puede reconstruir en español a partir del significado de las palabras que la conforman; por otra parte, esta misma unidad no acepta transformaciones morfosintácticas de ningún tipo. ${ }^{3}$

Los rasgos en cuestión (opacidad semántica y fijación estructural) han sido utilizados por muchos autores ${ }^{4}$ para diferenciar las locuciones de los compuestos sintagmáticos. Así, ha habido acuerdo en afirmar que estos últimos son semánticamente más transparentes que las locuciones y formalmente menos fijos. ${ }^{5}$ Sin embargo, parece ganar cada vez más consenso la idea de que ambos tipos de unidades presentan "grados" de idiomaticidad o de fijación. En efecto, el compuesto sala de estar (que es una sala para estar) es más transparente que hombre rana (que no es un hombre con características de rana) y que piel roja (que designa a un nativo de América, y no un tipo de piel); del mismo modo, hay locuciones con opacidad alta (sin ton ni son, a ojos vistas, mosquita muerta), opacidad media (el qué dirán, echar raices, a tientas) u opacidad baja o nula (sano y salvo, aqui y ahora). En cuanto al grado de fijación, es fácil comprobar que es igualmente variable en ambos tipos de unidades fraseológicas. Por ejemplo, mientras el compuesto reloj despertador admite pluralización en ambos componentes (relojes despertadores), media luna acepta plural ya sea en ambos constituyentes (medias lunas) o bien solo en uno de ellos (media lunas). ${ }^{6}$ De igual forma, la locución a pie puntillas rechaza cualquier cambio de tipo morfosintáctico, pero sano y salvo admite flexión de género y número (sanos y salvos/ sanas y salvas). No obstante lo dicho, repárese que ni compuestos ni locuciones aceptan reordenamiento de sus componentes $\left({ }^{*}\right.$ despertador reloj $\mathrm{y}{ }^{*}$ salvo y sano). En definitiva, la fijación ha de entenderse entonces en términos exclusivamente sintácticos.

En comparación con los compuestos y las locuciones, las colocaciones con verbo soporte más nombre de evento muestran ser semánticamente más transparentes y sintácticamente menos fijos. Volviendo al ejemplo anterior, echar una mirada no solo refiere el 'acto' de mirar, sino también el 'modo' en que se mira; además, la construcción no está "petrificada", por decirlo así (cfr. "Ernesto echó una mirada a su compañero" / "La mirada que Ernesto echó a su compañero"). ¿Cuáles son, entonces, los rasgos lingüísticos que hacen posible diferenciar las unidades fraseológicas entre sí? En este caso particular, no son ni la opacidad semántica ni la fijación sintáctica, y pese a ello les asignamos el valor de "frases" a expresiones como dar un paseo, tomar decisiones, prestar atención, hacer alarde, etc.

En consecuencia con lo expuesto hasta aquí, proponemos que la diferencia entre colocaciones con verbo soporte -por una parte- y compuestos (sintagmáticos) y locuciones

\footnotetext{
${ }_{3}^{3}$ Efectivamente, dorar la pildora no admite transformaciones como la pronominalización (*mi abuela la doró ayer), la pasivización (* la pildora fue dorada ayer), la intensificación (*dorar mucho la pildora) o la conmutación (* platearl pintar/tostar la pildora), ni transformaciones morfológicas en su componente nominal (*dorar las pildoras).

${ }^{4}$ Nos referimos, entre otros, a Buenafuente 2007, Corpas 1996, García-Page 2001, Ferrando 2002, Ruiz 2002 y Zuluaga 2002.

${ }_{5}^{5}$ Los datos muestran, contrariamente, que compuestos como caja fuerte no admiten conmutación ( ${ }^{*}$ caja potente), permutación $\left({ }^{*}\right.$ fuerte caja) ni relativización $\left({ }^{*}\right.$ la caja es fuerte). Es decir, son tan "fijos" como las locuciones.

${ }^{6}$ En países como Argentina el compuesto ya se encuentra lexicalizado (medialunas).
} 
-por otra-, reside en la presencia o ausencia de "fijación sintáctica", no morfológica. O sea, las colocaciones de verbo soporte (al contrario de los compuestos y las locuciones), carecen de fijación en el plano de la sintaxis y en cambio los compuestos y las locuciones (al contrario de las colocaciones de verbo soporte) son por definición estructuras sintácticamente fijas; no admiten, por tanto, el quiebre de la unidad mediante interpolación de elementos léxicos o gramaticales (en algunos casos) o mediante permutación de sus constituyentes, en otros (i.e. la colocación armar líos: "Ya no armes más lios" / "El lio (tremendo) que armó esta chica...", frente a la locución de chuparse los bigotes: "Este postre está de chuparse los bigotes" / "De chuparse los bigotes quedó este postre"/ *Mi padre se chupó otra vez los bigotes" / "Los bigotes a menudo se los chupa mi padre cuando lee" y frente al compuesto mesa de luz: "En cada habitación hay una mesita de luz"/ * "Me gustan las mesas cuando son de luz").

Del mismo modo, afirmamos que la diferencia entre compuestos (sintagmáticos) y locuciones no reside en el "grado" de fijación sintáctica -porque esta es una propiedad que comparten- sino en la función que cumplen en el sistema de la lengua: mientras los primeros surgen por necesidades "denominativas" de los hablantes, las segundas se crean por necesidades "expresivas". Es por este motivo que los compuestos normalmente no tienen un equivalente en la lengua (¿cómo nombrar en una palabra única en español aquello que se designa mediante sala de estar, piel roja, hora punta, cresta de la ola?), y en cambio las locuciones representan siempre una manera distinta, por lo general festiva e idiosincrásica de decir las cosas: el mosquita muerta es 'hipócrita'; el cabeza dura es 'testarudo'; dorar la pildora es 'engañar', “creer a pie juntillas” es creer 'ciegamente', etc. Y así es cómo, por ejemplo en español de Chile, nos enamoramos hasta las patas (dormimos a pata suelta, tenemos mala pata o metemos la pata), se nos hace agua la boca, vivimos a medio morir saltando, quedamos con la cola entre las piernas, etc., etc.

En relación con el carácter denominativo de los compuestos (sintagmáticos), vale destacar el hecho de que, lo que en algunas variantes dialectales del español se nombra por medio de dos o más palabras (por ejemplo, mesita de luz y tetera eléctrica en Argentina) en otras se nombra mediante una palabra única (por ejemplo, velador y hervidor en Chile). Ha de hacerse la observación de que las expresiones mesita de luz (o mesita de noche) y velador no son sinónimas, por cuanto no presentan alternancia en sus respectivas comunidades.

En síntesis, los rasgos de "idiomaticidad” y "fijación” pueden ser útiles para distinguir las llamadas combinaciones "libres" de las "fijas", pero no para distinguir entre compuestos, colocaciones (en el sentido en que lo hemos propuesto aquí) y locuciones. Por otro lado, en lugar de hablar de sintagmas libres o fijos, preferimos hablar de sintagmas más o menos "restringidos": el sintagma libro aburrido es menos restringido que el sintagma saciar el hambre y este, a su vez, menos restringido que año bisiesto. Efectivamente, la relación entre aburrido y libro es más laxa que la que se da entre saciar y hambre (en español, en sentido recto, saciamos el apetito, el hambre, la sed, y no mucho más), pero la que hay entre año y bisiesto es de implicación, por cuanto bisiesto solo se predica de año. Es el carácter fuerte de algunas restricciones léxicas de la lengua lo que ha llevado a afirmar a algunos que se trata de combinaciones fijas. 


\section{Metodología}

El método que se aplicó para esta breve investigación fue el análisis de datos provenientes de un corpus documental. Estos datos fueron cotejados con fuentes lexicográficas dialectales e históricas con dos propósitos fundamentales: i) observar si se encontraban registrados y/o definidos; ii) proponer para ellos una categorización de acuerdo con las clases de unidades léxicas pluriverbales descritas en el apartado anterior. Así, pues, quedaron excluidas de este análisis las fórmulas, los marcadores discursivos y las paremias, que esperamos poder estudiar en otra ocasión. consultadas.

Se expone a continuación la descripción del corpus y las fuentes lexicográficas

\subsection{El corpus}

El corpus que sirvió de base para esta investigación está compuesto por dos documentos que representan un valioso testimonio de la lengua espańola en Chile. Estos corresponden a una pequeńa muestra seleccionada desde la valiosa recopilación de literatura oral chilena realizada por Rodolfo Lenz entre fines del siglo XIX y comienzos del siglo XX en la zona central de este país.

El primer documento pertenece al "Fondo Rodolfo Lenz" que resguarda la Universidad Metropolitana de Ciencias de la Educación (UMCE) y se encuentra digitalizado en el portal de Memoria Chilena (www.memoriachilena.cl). Este documento corresponde a un manuscrito de 40 páginas en el que Lenz transcribió fonéticamente fragmentos y textos completos de poesía y narrativa del repertorio popular. La denominación de este documento dentro del "Fondo Rodolfo Lenz" es Adivinanzas II... y su descripción es "Adivinanzas, relances, esquinazos, cogollos, canciones de amor, de cuna, a lo divino, etc. Esta recopilación de poesía popular se acompaña de transcripción fonética”. El segundo documento pertenece a la sección del "Fondo Rodolfo Lenz" que preserva la Biblioteca Nacional de Chile, y corresponde a un manuscrito de dos páginas que contiene una narración de la literatura oral titulada La niña encantada.

Véase la siguiente tabla: 
Tabla 1: Descripción del corpus

\begin{tabular}{|l|l|l|l|}
\hline Identificación & Ubicación & Composición & Descripción \\
\hline MC0063306 & $\begin{array}{l}\text { Fondo Rodolfo Lenz } \\
\text { UMCE } \\
\text { Memoria Chilena }\end{array}$ & $\begin{array}{l}169 \text { textos de poesía } \\
\text { popular; } \\
5 \text { narraciones de ficción. }\end{array}$ & $\begin{array}{l}\text { Adivinanzas relances, } \\
\text { Adivinanzas, } \\
\text { esquinazos, cogollos, } \\
\text { canciones de amor, de } \\
\text { cuna, alodivino, etc. Esta } \\
\text { recopilación de poesía } \\
\text { popular se acompaña de } \\
\text { transcripción fonética. }\end{array}$ \\
\hline LO10046 & $\begin{array}{l}\text { Fondo Rodolfo Lenz } \\
\text { Biblioteca Nacional }\end{array}$ & 1 narración de ficción & $\begin{array}{l}\text { La niña encantada: } \\
\text { Cuento de la tradición } \\
\text { oral }\end{array}$ \\
\hline
\end{tabular}

\subsection{Las fuentes lexicográficas}

Las unidades fraseológicas identificadas en el corpus de trabajo fueron consultadas en fuentes lexicográficas dialectales e históricas, según ya se señaló. La pesquisa se realizó teniendo en cuenta no solo la aparición de la pieza léxica en la entrada del artículo lexicográfico, sino también dentro de este (en la definición, en las notas o en los ejemplos, en caso de haberlos). Las fuentes consultadas fueron las siguientes:

i) Diccionario ejemplificado de chilenismos (1984-1987), en adelante DECh.

ii) Diccionario etimológico de las voces chilenas derivadas de lenguas indígenas americanas (1905-1910), en delante $\mathrm{DE}^{7}$.

iii) Diccionario de chilenismos y de otras voces y locuciones viciosas (1901-1918), en adelante DChVLV

iv) Diccionario de chilenismos (1875), en adelante Dch.

Adicionalmente, se consultaron, en el Corpus Diacrónico del Español (CORDE), las concordancias completas o parciales de las unidades en cuestión, especialmente las atingentes a Chile, con el objeto de hallar posibles contraejemplos que pusieran en duda la calidad de 'frasemas' de estas piezas, así como para poder reunir otros contextos de uso que arrojaran luces sobre las propiedades semánticas de estas mismas.

\footnotetext{
${ }^{7}$ Esta consulta solo procedió en aquellas unidades fraseológicas que contenían algún posible indigenismo.
} 


\section{Resultados}

Se exponen a continuación los resultados y principales hallazgos de la búsqueda de testimonios de unidades léxicas pluriverbales en este corpus diacrónico de la lengua española en Chile. En primer lugar se presentan los casos adscritos a una u otra clase de unidades fraseológicas, y a continuación su descripción en términos semánticos y sintácticos.

\subsection{Compuestos Sintagmáticos}

Se encontraron tres testimonios de compuestos sintagmáticos en el corpus: ojota minera, sombrero guarapón y manta cari. De estos, solo sombrero guarapón tuvo coincidencia en el CORDE, tratándose precisamente de un testimonio chileno del año 1882: "con su correspondiente poncho y sombrero guarapón". Por su parte, ojota minera aparece en todos los diccionarios, excepto en el DECh, en tanto que sombrero guarapón está incorporado en el DE como entrada.

Al lado de estos, figura el sintagma manta cari, que en los diccionarios objetos de revisión se incorpora en la entrada de cari (o kari) y cuya definición remite a un tipo de “manta de oveja, de color pardo o plomizo". En la última versión del diccionario académico, el uso del adjetivo cari se adscribe solo a Argentina y aparece restringido al sustantivo manta. La implicación léxica que guardan entre sí estas dos palabras puede explicar que incluso en la actualidad manta cari se interprete como una sola unidad ${ }^{8}$.

La revisión en las fuentes lexicográficas permite confirmar que cada uno de estos compuestos designa una realidad material y cultural concreta, es decir, que cumplen una función designativa, propiedad central de los compuestos.

\subsection{Colocaciones}

Se hallaron dos testimonios que pueden corresponder a colocaciones verbonominales, de acuerdo con la definición que se ha adoptado en este trabajo: meter un mormullo y meter bulla. Tan solo meter bulla presentó coincidencias en el CORDE.

Las colocaciones meter bulla y meter un mormullo corresponden a construcciones con verbo soporte, si se atiende al hecho de que la predicación descansa en los nombres respectivos. El DECh incluye en la entrada de bulla la nota "U.m.c.CD de meter", lo que significa que entre el nombre y el verbo hay una relación semántica restrictiva. La voz mormullo es una variante histórica de murmullo y comparte con bulla los rasgos [+acústico] y [+desapacible] de acuerdo con la revisión que se hizo en diccionarios históricos y en CORDE. La construcción meter bulla mantiene vigencia (CORDE Hispanoamérica: 11 casos en 11 documentos), pero meter un mormullo puede considerarse una variante histórica de esta colocación que no estaría registrada en las fuentes consultadas.

\footnotetext{
${ }^{8}$ Cari o manta cari es de uso rural.
} 


\subsection{Locuciones}

El grupo de las locuciones posee 17 testimonios en total. Once de ellos están registrados en alguna de las fuentes lexicográficas chilenas, y siete mostraron coincidencias válidas en el CORDE.

Las locuciones que se encuentran recogidas completa o parcialmente en DECh son hacer lo que dios manda, saber lo que es canela, a ver si (ronca la vieja), hacérsela con (un real), al tirante, nada se le hace, con el poto agarrado, patas para arriba y parar la oreja. Por su parte, medio leso y a pequenadas se encuentran incorporadas en el DChVLV y en el DE respectivamente.

Las restantes seis locuciones no se encontraron registradas en las fuentes lexicográficas consultadas con el sentido dado en el corpus. Los casos de corazón de chifle y chafla y tener más amigos que la uva corresponderían a locuciones que presentan menor grado de fijación que otras construcciones, pero que dan cuenta de una estructura que en la actualidad se ha convertido en un mecanismo de creación léxica que ha generado construcciones más fijas. Así, tener más amigos que la uva contiene la estructura "tener más amigos que", la cual, pese a no figurar en el CORDE, es de uso actual en Chile. Por su parte, corazón de chifle y chafla, si bien puede considerarse como una creación léxica singular, contiene también el germen de una estructura con vigencia, "corazón de", que posibilita construcciones como corazón de mantequilla o corazón de abuelita, que sí recoge el DECh.

Otros casos no recogidos en los repertorios lexicográficos chilenos son al ojo, con las hilachas colgando, presa por presa y poner asiento y servicio. La primera de estas alude al modo de usar el sombrero cubriendo parte de la vista, sentido que se puede corroborar por medio del cotejo con el único testimonio hallado en CORDE: "se bajó el kepí al ojo e inclinó la cabeza para no ver aquella escena de sangre" (Chile, 1845). La locución con las hilachas colgando alude a la forma poco pulcra de vestir o a la pobreza del atuendo, sentido que conserva en Chile pero que en Argentina al parecer ha evolucionado, según se constata en una de las pocas coincidencias que arroja el CORDE: "Esa tendencia del hombre a terminar limpiamente lo que hace, sin dejar hilachas colgando" (Argentina 1963). Si bien presa por presa puede considerarse una locución bastante menos opaca que la locución anterior, es interesante señalar el uso figurado de la variante dialectal que representa este testimonio ('parte por parte', 'una a una', en referencia a las partes del cuerpo). Finalmente, está poner asiento y servicio, que no presentó coincidencias de ningún tipo. En Chile, se llama servicio al cubierto, de modo que la expresión podría significar "dar un puesto en la mesa (a alguien)", atender sus necesidades de comida y bebida.

\section{DESCRIPCIÓN DE LAS UNIDADES LÉXICAS PLURIVERBALES}

A continuación presentamos la descricipción de cada una de las unidades léxicas complejas halladas en nuestro corpus con la información gramatical y enciclopédica que 
permite comprender su sentido. Hemos consignado las definiciones encontradas, mientras que para aquellos casos no registrados los diccionarios consultados o cuya definición no se ajusta a nuestros testimonios ofrecemos una propuesta de definición. Finalmente, presentamos el contexto del testimonio en cuya transcripción se ha intentado respetar la representación gráfica del manuscrito original:

\subsection{Compuestos}

\section{Ojota minera}

El DE registra s.v. ojota la construcción ojota minera definida como "sandalia parecida (a la ojota chacarera) pero más grande que cubre tb. el pie por encima, como zapato". En el DECh s.v. ojota se señala la existencia de dos tipos: la ojota chacarera y la ojota minera. Testimonio registrado en nuestro corpus: Señora doña María, yo vengo de La Calera, $y$ ar niño e Dioh le traigo unas ojotah minerah.

\section{Sombrero guarapón}

El DECh registra s.v. guarapón la definición "sombrero de copa redonda y alas anchas horizontales, hecho de fieltro o de paja que se usaba para protegerse del sol". El DE registra s.v. huarapón la construcción sombrero huarapón que se define como "sombrero de paja o paño de alas anchas". Ahí también se señala la variante guarapón. Testimonio registrado en nuestro corpus: ehtoy queriendo un rotito, toah las señah le doy, anda con mantita kári y un sombrero guarapón.

\section{Manta cari}

El DECh registra s.v. cari la definición "de color gris, café, pardo o plomizo en sus diferentes tonalidades claras y oscuras. Aplícase m. a paño o tejido”. El DE s.v. cari señala que es un "color difícil de determinar" ya que según algunas referencias podría ser pardo o gris, entre café y amarillo, o bien color salmón. Más adelante señala que "se dice espec. de la lana de ovejas, de mantas y ponchos". Según el DE cari provendría de la lengua mapuche y significaría 'verdoso'. Testimonio registrado: ehtoy queriendo un rotito, toah las señah le doy, anda con mantita kári, y un sombrero guarapón.

\subsection{Colocaciones}

Meter un murmullo

Esta construcción no fue encontrada en las fuentes lexicográficas consultadas. Proponemos definirla como 'provocar un ruido intranquilizador'. Testimonio registrado: 
se te hace!"

Llegó la gente, señor. Le metieron un mormollo, una bulla. Le ecian: “H'Hábla! quie ná Meter (una) bulla

El DECh registra s.v. bulla que esta voz se usa más como CD del verbo meter y se define como "ruido prologado o reiterado, generalmente desapacible". La voz bulla es panhispánica y significa de 'griterío o ruido'. Testimonio registrado: Llegó la gente, señor. Le metieron un mormollo, una bulla. Le ecian: “Hábla! quie ná se te hace!”.

\subsection{Locuciones}

Corazón de chifle y chafla

Esta construcción no fue encontrada en las fuentes lexicográficas consultadas. Proponemos definirla como 'persona presuntuosa'. Testimonio registrado: Corazón de chifle y chafla, aforrao en terciopelo, como queri que chifle, si otro te chifló primero.

Aversi

El DECh registra s.v. ver la construcción vamos a ver que se describe de la siguiente forma: "anuncia la decisión de esperar que lo que sucede haga patente la certeza que se tiene de algo o la posibilidad de su realización (sic)". Ahí también se señala que presenta un valor semejante al de la frase castiza a ver, veamos, también usual en Chile. Testimonio registrado: asómate a la ventana, a ver si ronca la vieja, y se acaso ehta durmiendo, dale un tirón en la oreja.

\section{Hacérsela con}

El DECh registra s.v. hacer la construcción hacérsela a uno con algo definida como "convidarlo con lo que se menciona". Testimonio registrado: qué viva er señor don Juanito, cogollito de peral, meta la mano ar borsillo, y hágamela con un real.

Tener más amigos que la uva

Esta construcción no fue encontrada en las fuentes lexicográficas consultadas. Proponemos la definición 'ser alguien muy popular'. Testimonio registrado: tiene más amigoh que la uva.

Poner asiento y servicio

Esta construcción no fue encontrada en las fuentes lexicográficas consultadas. Proponemos la definición 'atender con hospitalidad'. Testimonio registrado: Llegando ahí le 
pusieron asiento y servicio, y no sabia quién le servía. Lo sirvieron ahi con comía i armuerzo...

Medio leso

El DChVLV registra s.v. leso la construcción medio leso descrita de la siguiente forma "se le dice a uno para suavizarle el insulto, diciéndole leso entero o a secas". El chilenismo leso significa 'tonto, necio' (DChVLV y Dch). Testimonio registrado: de tontos $y$ medioh lesoh, tengo una petaca llena, y al que quera compral, a medio doy la docena.

Con el poto agarrado

El DECh registra s.v. poto la construcción agarrarse el poto a dos manos y se la define como "pasar mucha aflicción”. El DECh registra la variantes con el poto a dos manos y con el poto agarrado. Proponemos la definición 'pasar mucho susto'. Testimonio registrado: $Y$ llegaban a ecir, ya murió hte condenao, que los hacia correl, con er potito agarrao.

A pequenadas

En el DE se registra s.v. pequén el derivado vulgar andar con (a)pequena(d)as definida como "provocar a otro indirectamente". El pequén según esta misma fuente es una "lechuza muy común". Testimonio registrado: De la cordillera vengo, a caballo en un pequén, él a pequenah conmigo, y yo a pequenah con él.

Al ojo

Esta construcción no fue encontrada en las fuentes lexicográficas consultadas. Proponemos la siguiente definición 'se aplica al tocado o sombrero, y esp. A la forma de llevarlo'. Testimonio registrado: Me guhta ver a loh roto, cuando ehtan enamorao, con la chupallita al ojo, y las hilachah corgando.

(Andar alguien con) las hilachas colgando

Esta construcción no fue encontrada en las fuentes lexicográficas consultadas. Proponemos la definición 'andrajosamente'. Testimonio registrado: Me gubta ver a loh roto, cuando ehtan enamorao, con la chupallita al ojo, y las hilachah corgando.

Patas (para) arriba

El DECh registra s.v. patas la construcción patas para arriba y se define como "patas arriba; al revés o vuelto de abajo hacia arriba". Testimonio registrado: Mariquita sin sangre, parió un muñeco, con lah patah pa arriba, y el poto güeco". 
Presa por presa

Esta construcción no fue encontrada en las fuentes lexicográficas consultadas. Proponemos la definición 'referido a las partes del cuerpo, una a una'. Testimonio registrado: Entonceh le pegaron machetazoh, garrotazoh, y lo cortaron presa por presa. Entonceh vino la niña y lo puso en una mesa y lo compuso presa por presa.

(Nada) se le hace

El DECh registra s.v. hacer la construcción hacérsele a uno definida como "helársele a uno". Proponemos la definición 'experimentar mucho miedo'. Testimonio registrado: Le metieron un mormollo, una bulla. Le ecian: “Hábla! Quie ná se te hace!". No habló nunca.

Lo que dios manda

El DECh registra s.v. como dios manda la definición "como debe ser". Se señala además la variante que dios manda. Testimonio registrado: Vamoh niñas a la cama, a hacel lo que dios manda.

Al tirante

El DECh se registra s.v. al tirante la definición "altiro", chilenismo que significa "en el acto, inmediatamente". Testimonio resgistrado: ar tirante me quisihte, ar tirante me orbidahte; como el amor eh tirante, tiranteando me dejahte.

Lo que es canela

El DECh registra s.v. canela la construcción lo que es canela definidica como "lo que es bueno. U. $\mathrm{M}$ en sentido irónico". Testimonio registrado: er que no sabe de amor, no sabe lo que es canela.

Parar la oreja

El DECh registra s.v. oreja la construcción parar la(s) oreja(s) definida como "aguzar las orejas; prestar mucha atención”. Testimonio registrado ehta noche eh noche buena, noche de paral la oreja, asómate a la ventana, a ver si ronca la vieja.

En total se hallaron 22 unidades léxicas pluriverbales dentro del corpus consultado, las que fueron sometidas a examen de acuerdo con los criterios expuestos en el marco teórico de este trabajo. De ellas, solo catorce se encontraban registradas en las fuentes lexicográficas revisadas, en tanto que la consulta en el CORDE dentro de fuentes chilenas 
solo arrojó nueve coincidencias. No obstante, algunas unidades léxicas fueron halladas tanto en diccionarios como en CORDE. La tabla siguiente detalla estas relaciones:

Tabla 2. Resumen de unidades fraseológicas del corpus

\begin{tabular}{|l|c|c|c|}
\hline Clase & En diccionarios & En CORDE Chile & No documentados \\
\hline Compuestos & 2 & 1 & 1 \\
\hline Colocaciones & 1 & 1 & 1 \\
\hline Locuciones & 11 & 7 & 4 \\
\hline Totales & $\mathbf{1 4}$ & $\mathbf{9}$ & $\mathbf{6}$ \\
\hline
\end{tabular}

El corpus del que se obtuvo la muestra contiene también dichos (fórmulas) y expresiones paremiológicas, del tipo iqué barbaridad!; el que escupe al cielo, a la cara le cae; al que le venga el sayo, que se lo ponga; el que tiene tienda, que la atienda; quién te peló, que las orejas te dejó, etc. Pero de estas unidades, de naturaleza más bien textual, nos ocuparemos en otro trabajo.

\section{Conclusiones}

Los resultados de este trabajo exploratorio dedicado a las unidades léxicas complejas presentes en un corpus documental, han aportado datos interesantes para la historia de la lengua espańola en Chile, sobre todo en lo que respecta al hallazgo de compuestos, colocaciones y locuciones no testimoniadas hasta ahora en fuentes lexicográficas históricas y dialectales.

Sin lugar a dudas, trabajar con fuentes documentales históricas conlleva una serie de dificultades relacionadas con la sistemática escasez de datos con que se cuenta. En efecto, durante el proceso de evaluación de las unidades léxicas surgieron problemas como que una cantidad importante de ellas no se encontraran registradas en las fuentes lexicográficas, o que no siempre haya sido posible comprobar las propiedades semántico-sintácticas de algunas piezas léxicas debido a la carencia de otros testimonios con los que hacer un contraste. Por esta razón, cabe la posibilidad de que no se hayan considerado en este análisis del corpus algunas unidades léxicas que deberían ser incluidas en alguna de estas categorías. En consecuencia, se hace necesario continuar el estudio de este y otros testimonios de época con los que establecer un contraste que permita comprobar el grado de fijación interna de ciertas piezas léxicas.

Por su parte, las propuestas de Osorio y Serra (2012) probaron ser de utilidad ya que su sistema clasificación permitió distinguir claramente entre unidades léxicas que 
por su naturaleza difícilmente se pueden sumir en categorías estancas. Por tal razón se hace sumamente práctico considerar que, en efecto, este tipo de unidades son parte de un continuum que puede aceptar diferentes grados de matices en sus propiedades.

Finalmente, se pudo comprobar que algunas de estas unidades léxicas pluriverbales pueden ser examinadas en perspectiva diacrónica para observar posibles cambios en curso, los que en algunos casos han llevado a una mayor fijación de la estructura sintáctica de algunas de estas unidades, o bien, a una mayor opacidad semántica, o ambas, tal como se pudo observar en algunos de testimonios descritos.

\section{Obras CiTADAS}

Alonso Ramos, Margarita. 2004. Las construcciones con verbo de apoyo. Madrid: Visor Libros. . 2007. Actantes y colocaciones. Nueva Revista de Filología Hispánica LV, 2: 435-458.

2012. Naturaleza semántica de las colocaciones verbales. Meaning, Texts and other Exciting Things: Festschrift in Honour of Igor Mel'cuk. Apresjan, J., et al. (eds.). Moscow: Jazyki slavjanskoj kultury. 15-29. Web. 16 de octubre de 2018. Recuperado desde el sitio: http://www.ruslang.ru/doc/melchuk_festschrift2012/Ramos.pdf

Bosque, Ignacio. 2001a. Sobre el concepto de 'colocación' y sus límites, Lingüistica española actual 23, 1: 9-40.

. 2001b On the weight of light predicates. Features and interfaces in Romance. Essays in honor of Heles Contreras. Herschenson, K. Zagona y E. Mallén (eds.). Amsterdam: John Benjamins. 23-38.

2004. La direccionalidad en los diccionarios combinatorios y el problema de la selección léxica. Lingüistica Teòrica: Anàlisi i perspectives I, Teresa Cabré Monné (ed.). Barcelona: Catalan Journal of Linguistics Monographies. 13-58.

. 2011. Deducing Collocations. Proceedings of the 5th International Conference on Meaning-Text Theory, I. Boguslavsky \& L. Wanner (eds.), Barcelona, vi-xxiii.

Buenafuente, Cristina. 2007. Procesos de gramaticalización y lexicalización de compuestos en español. Tesis doctoral, Universitat Autònoma de Barcelona.

Corpas Pastor, Gloria. 1996. Manual de fraseología española. Madrid: Gredos.

De Miguel, Elena. 2008. Construcciones con verbo de apoyo en español. De cómo entran los nombres en la órbita de los verbos. Actas del XXXVII Simposio Internacional de la Sociedad Española de Lingüistica (SEL). Universidad de Navarra, Pamplona.

2011. En qué consiste ser verbo de apoyo. 60 problemas de gramática dedi-

cados a Ignacio Bosque. María Victoria Escandell, Manuel Leonetti, María Cristina Sánchez (coords.). AKAL. 139-146.

Ferrando Aramo, Verónica. 2002. Colocaciones y compuestos sintagmáticos: dos fenómenos léxicos colindantes. Cuestiones de lexicografía. Pérez Pascual, José Ignacio y Mar Campos Souto (eds.). Lugo: Tris Tram. 99-107. 
García-Page, Mario. 2001. ¿Son las expresiones fijas expresiones fijas?, Moenia 7: 165-197. Mel'cuk, Igor. 1996. Lexical functions: a tool for the description of lexical relations in a lexicon., Lexical functions in lexicography and natural language processing. L. Wanner (ed.). Amsterdam: J. Benjamins. 37-102. . 2001. Fraseología y diccionario en la lingüística moderna. Presencia y renovación de la lingüistica francesa. I. Uzcanga Vivar et al. (eds.). Salamanca: Universidad de Salamanca. 267-310.

Osorio Olave, Gabriela, y Susana Serra Sepúlveda. 2012 Colocaciones, compuestos sintagmáticos y locuciones nominales: hacia un intento de delimitación conceptual. Lenguas Modernas 9: 103-116.

Real Academia Española. 2010. Nueva gramática de la lengua española: Manual Madrid: Espasa Calpe. . 2009. Nueva gramática de la lengua española. Madrid: Espasa Calpe.

Ruiz Gurillo, Leonor. 2002. Compuestos, colocaciones, locuciones: intento de delimitación. Léxico y gramática. González Pereira, Miguel; Montserrat Souto Gómez y Alexandre Veiga (eds.). Lugo: Tris Tram. 327-339.

Zuluaga, Alberto. 2002. Los 'enlaces frecuentes' de María Moliner. Observaciones sobre las llamadas colocaciones. LEA 24: 97-114.

\section{REFERENCIAS LEXICOGRÁFICAS}

Bosque et al. 2004. REDES, diccionario combinatorio del español contemporáneo. Madrid: Ediciones SM.

Real Academia Española. 2014. Diccionario de la lengua española (DRAE). Madrid: Espasa Calpe.

\section{FUENTES LEXICOGRÁFICAS}

DE: Lenz, Rodolfo. 1905-1910. Diccionario etimológico de las voces chilenas derivadas de lenguas indígenas americanas. Ed. Mario Ferrecio Podestá. Santiago: U. de Chile. Web. 16 de octubre de 2018. Disponible en Memoria Chilena, Biblioteca Nacional de Chile. http://www.memoriachilena.cl/602/w3-article-9895.html

DECh: Morales Pettorino, F. et al. 1984-1987. Diccionario ejemplificado de chilenismos y de otros usos diferenciales del español de Chile. Academia Superior de Ciencias Pedagógicas de Valparaíso.

DCh: Rodríguez, Zorobabel. 1875. Diccionario de chilenismos. Santiago: Imprenta El Independiente. Web. 16 de octubre de 2018. Disponible en Memoria Chilena, Biblioteca Nacional de Chile http://www.memoriachilena.cl/602/w3-article-8463.html. 
ESTUDIOS FILOLÓGICOS

DVChLV: Román, Manuel Antonio. 1901-1918. Diccionario de chilenismos y de otras voces $y$ locuciones viciosas. Santiago: Imprenta San José. Web. 16 de octubre de 2018. Disponible en Memoria Chilena, Biblioteca Nacional de Chile http://www.memoriachilena.cl/602/w3-article-85595.html.

\section{PÁGINAS WEB}

Memoria Chilena. <http://www.memoriachilena.cl>

Real Academia Española: Banco de datos (CORDE) [en línea]. Corpus diacrónico del español. <http://www.rae.es> 


\begin{tabular}{|c|c|c|c|c|c|c|c|c|}
\hline 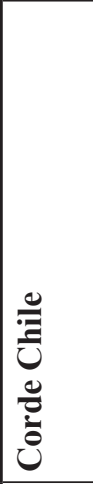 & 0 & 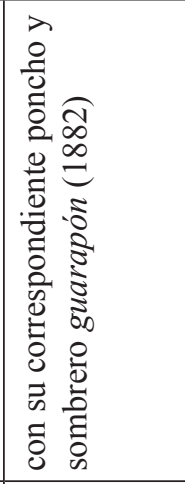 & 0 & 0 & 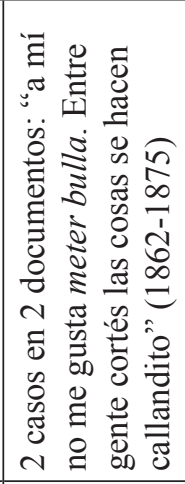 & 0 & 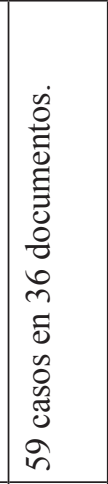 & 0 \\
\hline$\underset{\substack{0 \\
\frac{0}{0}}}{\stackrel{0}{a}}$ & 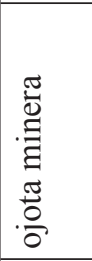 & 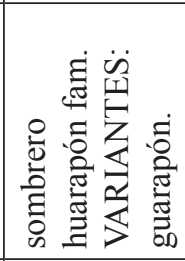 & 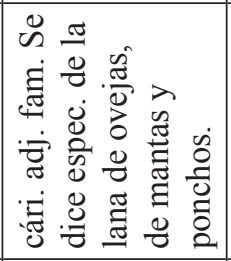 & \begin{tabular}{l}
1 \\
\\
\hdashline \\
\end{tabular} & $\overleftrightarrow{Z}$ & $\stackrel{\circ}{Z}$ & $\overleftrightarrow{\mathrm{z}}$ & $\overleftrightarrow{\mathrm{z}}$ \\
\hline 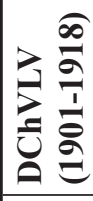 & 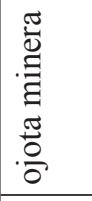 & 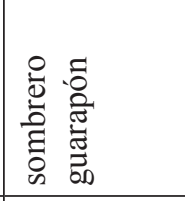 & שٓ & $\stackrel{0}{Z}$ & $\begin{array}{l}0 \\
z\end{array}$ & $\begin{array}{l}0 \\
Z\end{array}$ & $\begin{array}{l}0 \\
Z\end{array}$ & 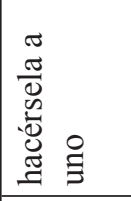 \\
\hline ప & 용. & 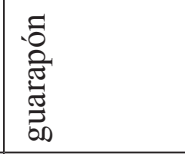 & $\begin{array}{l}\text { II } \\
\text { U }\end{array}$ & Z & Z & $\begin{array}{l}\circ \\
Z\end{array}$ & $\stackrel{\circ}{Z}$ & Z \\
\hline 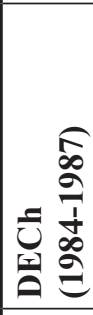 & $\frac{\pi}{0}$ & 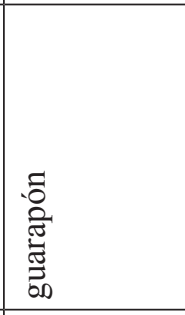 & 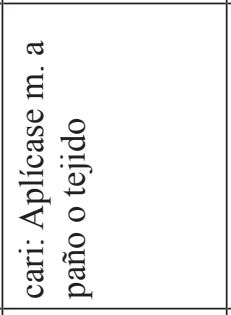 & そ & 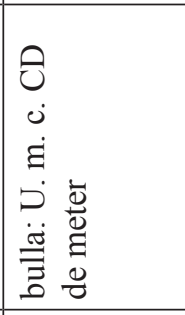 & そ & 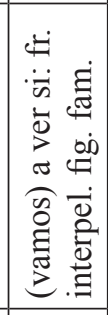 & 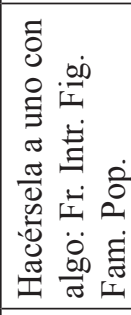 \\
\hline 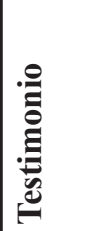 & 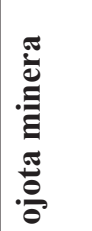 & 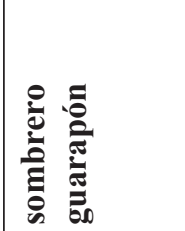 & 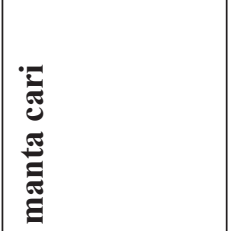 & 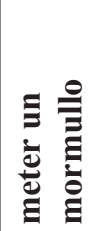 & 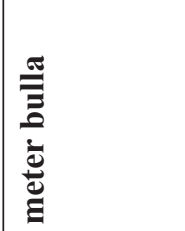 & 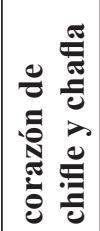 & 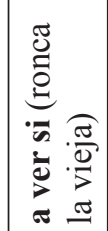 & 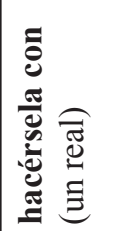 \\
\hline 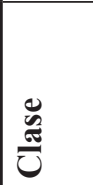 & 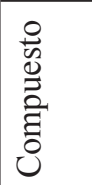 & 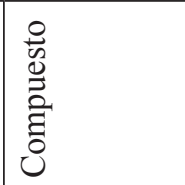 & 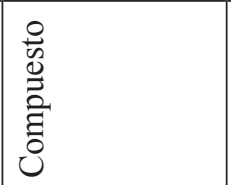 & $\begin{array}{l}0 \\
: 00 \\
0 \\
0 \\
0 \\
0 \\
0\end{array}$ & 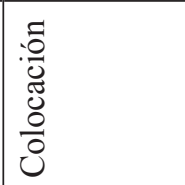 & 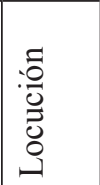 & 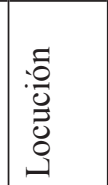 & 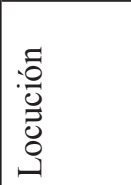 \\
\hline
\end{tabular}




\begin{tabular}{|c|c|c|c|c|c|c|c|c|c|}
\hline 0 & 0 & 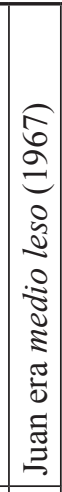 & 0 & 0 & 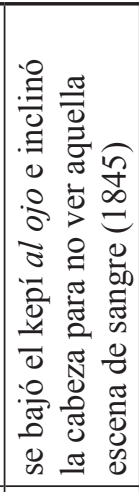 & . & 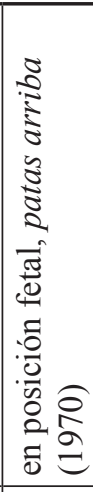 & 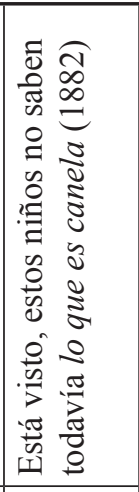 & 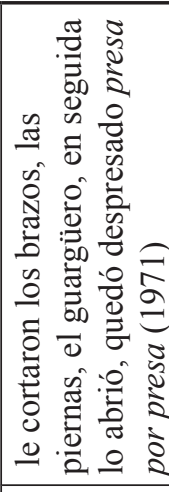 \\
\hline$\frac{\pi}{z}$ & $\overleftrightarrow{z}$ & $\overleftrightarrow{Z}$ & $\begin{array}{l}0 \\
: \\
2\end{array}$ & 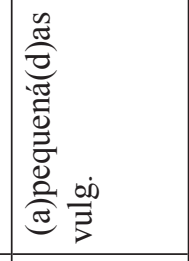 & $\overleftrightarrow{\Delta}$ & $\overleftrightarrow{Z}$ & $\begin{array}{l}0 \\
z\end{array}$ & $\frac{\varangle}{z}$ & 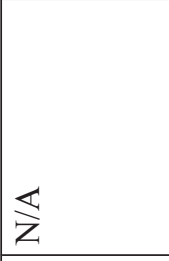 \\
\hline z & 号 & \begin{tabular}{|l|}
0 \\
0 \\
0 \\
0 \\
0 \\
$:$ \\
0 \\
$\Xi$ \\
$\Xi$ \\
\end{tabular} & $\stackrel{0}{\circ}$ & 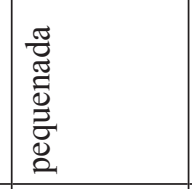 & 0 & z & $\stackrel{8}{z}$ & \& & z \\
\hline ○ & そ) & $\begin{array}{l}0 \\
\dot{\mathscr{\theta}} \\
\end{array}$ & $\begin{array}{l}0 \\
: \\
2\end{array}$ & 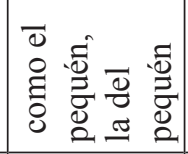 & ○ & z & そ) & $\stackrel{0}{z}$ & z \\
\hline$\stackrel{\circ}{z}$ & そ & \begin{tabular}{l}
0 \\
$\mathscr{B}$ \\
\hdashline \\
\end{tabular} & 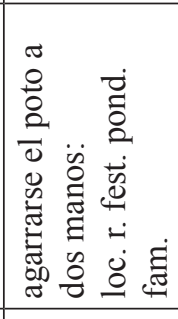 & 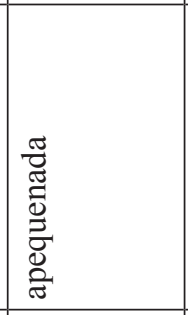 & そ & z & 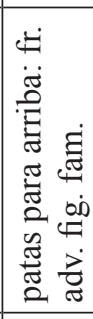 & \begin{tabular}{|l} 
\\
\end{tabular} & \& \\
\hline 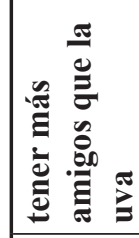 & 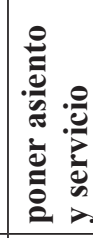 & 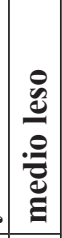 & 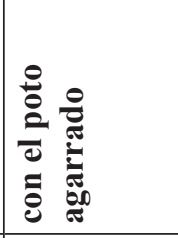 & 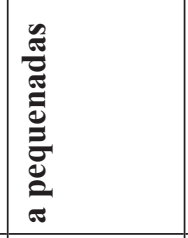 & $\frac{\stackrel{\circ}{\sigma}}{\sigma}$ & 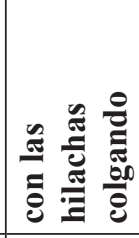 & 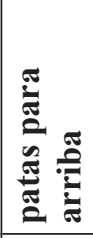 & 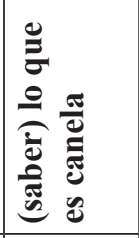 & 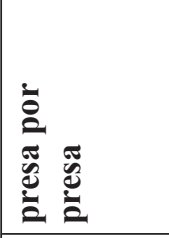 \\
\hline 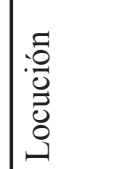 & 苞 & 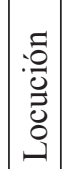 & $\mid \begin{array}{l}0 \\
000 \\
0 \\
0 \\
0 \\
0\end{array}$ & 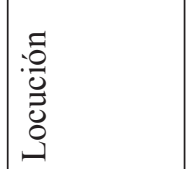 & 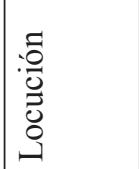 & 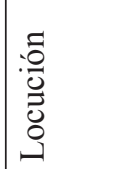 & 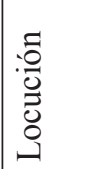 & 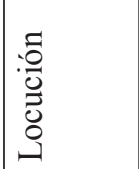 & 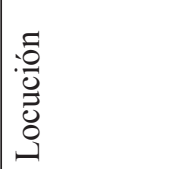 \\
\hline
\end{tabular}




\begin{tabular}{|c|c|c|c|c|}
\hline$\stackrel{̊}{Z}$ & 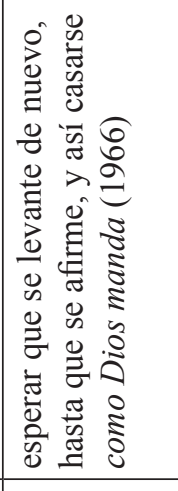 & 0 & 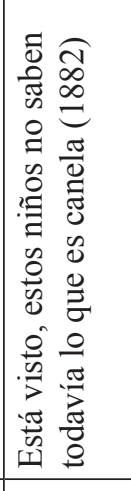 & 0 \\
\hline$\underset{\mathrm{Z}}{\mathbb{Z}}$ & $\overleftrightarrow{\Sigma}$ & 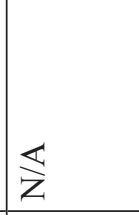 & $\overleftrightarrow{\text { Z }}$ & 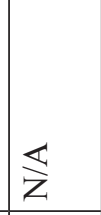 \\
\hline $\begin{array}{l}0 \\
Z\end{array}$ & $\stackrel{\circ}{Z}$ & そ) & Z & 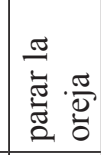 \\
\hline$\stackrel{゚}{Z}$ & $\stackrel{0}{Z}$ & $\frac{\stackrel{\ominus}{\Xi}}{\frac{\Xi}{\sigma}}$ & $\stackrel{\wp}{Z}$ & そ \\
\hline 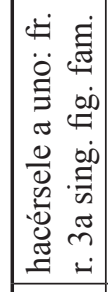 & 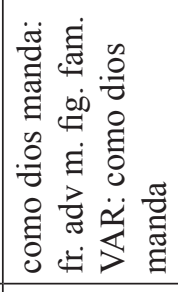 & 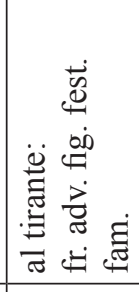 & 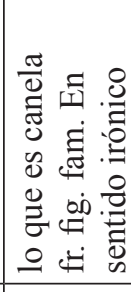 & 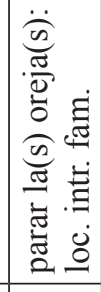 \\
\hline 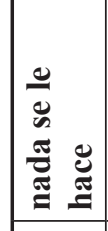 & 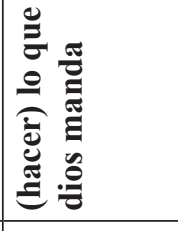 & 窇 & 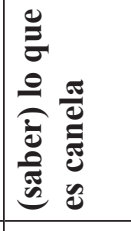 & 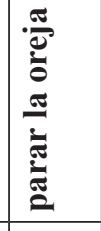 \\
\hline 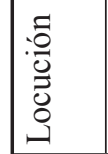 & 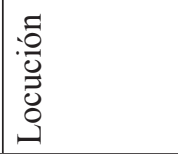 & 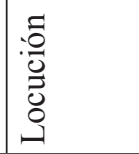 & 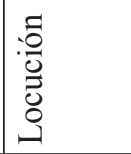 & 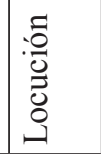 \\
\hline
\end{tabular}

